\title{
Synergy of Combined (S)TEM Imaging Techniques for the Characterization of Catalyst Behavior During In-Situ Heating
}

\author{
Jane Y. Howe, ${ }^{*}$ Lawrence F. Allard,* Wilbur C. Bigelow** and Steven H. Overbury,* \\ *Physical Sciences Directorate, Oak Ridge National Laboratory, Oak Ridge, TN 37831 \\ **Department of Materials Science \& Engineering, University of Michigan, Ann Arbor, MI 48104
}

Gold nanoparticles have generated considerable interest for catalytic applications for certain oxidation reactions [1]. Recently, a series of $\mathrm{Au}$ catalysts supported on $\mathrm{Fe}_{2} \mathrm{O}_{3}$ (hematite) were characterized with atomic resolution during elevated temperature treatments, using a novel in-situ heating technology (Protochips Aduro ${ }^{\mathrm{TM}}$ ) in an aberration-corrected STEM (JEOL 2200FS fitted with a CEOS GmbH hexapole corrector on the probe-forming lenses) [2]. In the present work, we extended the study to take advantage of the imaging capabilities in both STEM and TEM modes available in an Hitachi HF-3300 microscope, operated at $300 \mathrm{kV}$. This instrument is fitted with a secondary electron (SE) detector, in addition to both bright-field (BF) and high-angle annular darkfield (HAADF) detectors for STEM imaging, and a Gatan 2k x 2k Ultrascan CCD camera for TEM imaging. The advantage of TEM recording during in-situ heating is the short exposure times $(\sim 1 \mathrm{sec})$ relative to the slower scans required by STEM modes. This allows higher accuracy and more reliable analysis of the atomic structure via computed diffractograms (sample drift and scan artifacts can strongly affect STEM diffractograms). The capability of SE imaging in the Hitachi HF-3300 even at the high temperature afforded by the Protochips Aduro ${ }^{\mathrm{TM}}$ heater system is an added benefit for complementary analysis of catalyst structure and behavior during elevated temperature treatments. SE imaging has been coupled with STEM and TEM imaging in the present study.

A World Gold Council $\mathrm{Au} / \mathrm{Fe}_{2} \mathrm{O}_{3}$ (hematite) catalyst sample initially treated to leach away surface $\mathrm{Au}$ nanoparticles and other Au species was deposited onto an Aduro ${ }^{\mathrm{TM}}$ chip by dry-dipping the chip into the catalyst powder. Earlier studies [2] showed the presence of voids in the hematite support particles, as well as some Au nanoparticles and highly dispersed Au species internal to the support and coating the void surfaces. At $250^{\circ} \mathrm{C}$, no significant changes were observed for the voids or catalysts, but at $500^{\circ} \mathrm{C}$ the voids diminished in size and gradually disappeared, while internal $\mathrm{Au}$ species diffused to the surfaces to form new 1-2nm Au nanoparticles. In the present study, BF TEM images of a support particle are shown before heating (Fig. 1a) and after several minutes of heating at $500^{\circ} \mathrm{C}$ (Fig. 1b). A diffractogram from the particle in Fig. 1b shows periodicities consistent with $d$-spacings for the $<112>$ zone axis orientation of magnetite $\left(\mathrm{Fe}_{3} \mathrm{O}_{4}\right)$, indicating the reduction of the hematite particles during heating to $500^{\circ} \mathrm{C}$ in vacuum. Internal voids were observed to shrink during heating at $500^{\circ} \mathrm{C}$, an observation consistent with earlier results [2].

Further heating at a higher temperature caused a gradual appearance of Au nanoparticles in the 1$2 \mathrm{~nm}$ range on the surface of the leached catalyst support. The behavior of these nanoparticles is observed in Fig. 2, which shows a series of unprocessed SE images taken at $700^{\circ} \mathrm{C}$. Figure 2 a shows a relatively smooth surface at the beginning of the $700^{\circ} \mathrm{C}$ heating cycle and the presence of a number of $1 \mathrm{~nm}$ Au particles. In Figs. $2 \mathrm{~b}$ to $2 \mathrm{f}$, acquired over a few minutes, the support surface developed terraces, and some Au particles migrated on the terraces to coalesce into larger particles (e.g. as arrowed). This study demonstrates that $1 \mathrm{~nm}$ spatial resolution in SE imaging can be achieved even during in-situ heating at $700^{\circ} \mathrm{C}$. Such a combined SE and TEM in-situ study is useful for 
nanomaterials research because information from the surface via SE imaging and bulk via TEM/STEM imaging can be simultaneously obtained [3].

\section{References}

[1] Q. Fu, et al., Science 301: 935(2003)

[2] L.F. Allard, et al., J. Elect. Micros. 58(3): 199-212(2009).

[3] We thank Niels de Jonge for insightful discussions. This work was supported by the High Temperature Materials Laboratory, sponsored by the U.S. Department of Energy, Office of Energy Efficiency and Renewable Energy, Vehicle Technologies Program.
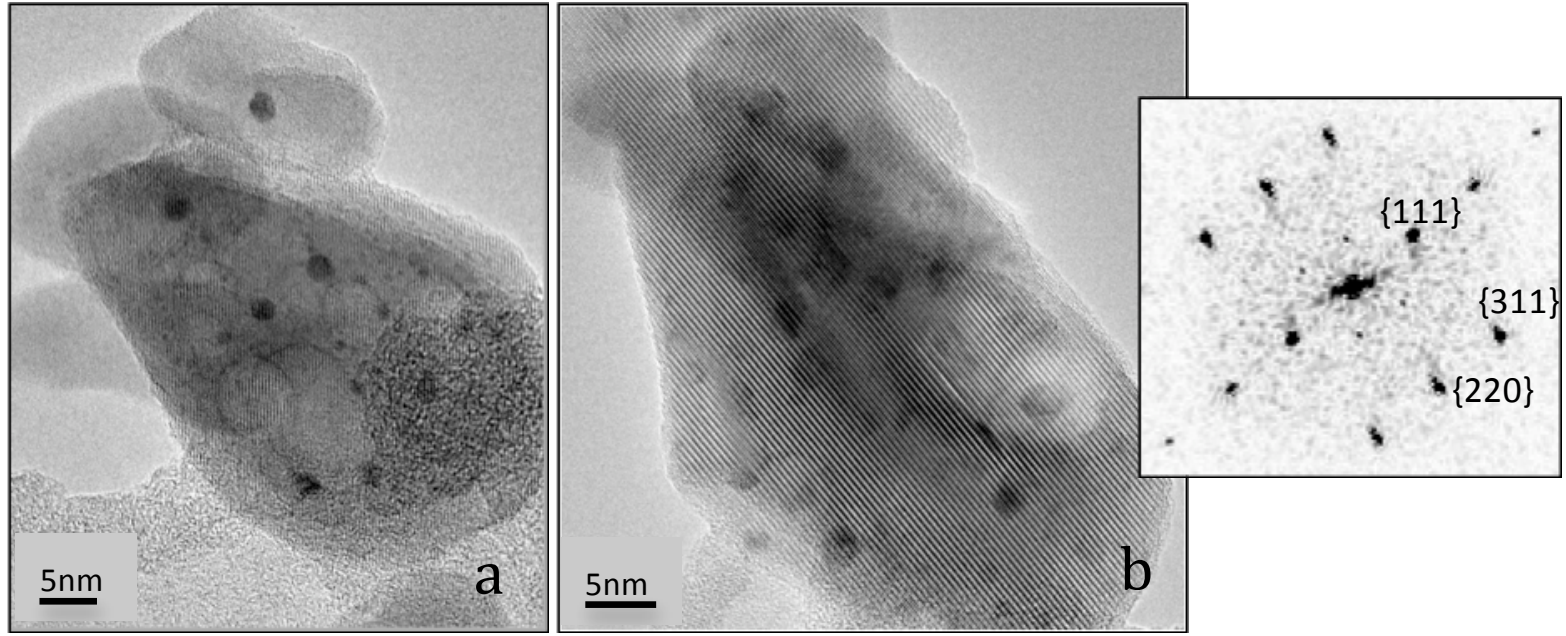

FIG. 1 a) Leached $\mathrm{Au} / \mathrm{FeOx}$ (hematite, $\mathrm{Fe}_{2} \mathrm{O}_{3}$ ) catalyst at room temperature, showing voids and Au nanoparticles in BF TEM; b) Same support particle imaged at $500^{\circ} \mathrm{C}$, showing Au particle growth and void shrinkage; c) diffractogram from heated particle, consistent with a $<112>$ zone axis of magnetite $\left(\mathrm{Fe}_{3} \mathrm{O}_{4}\right)$.
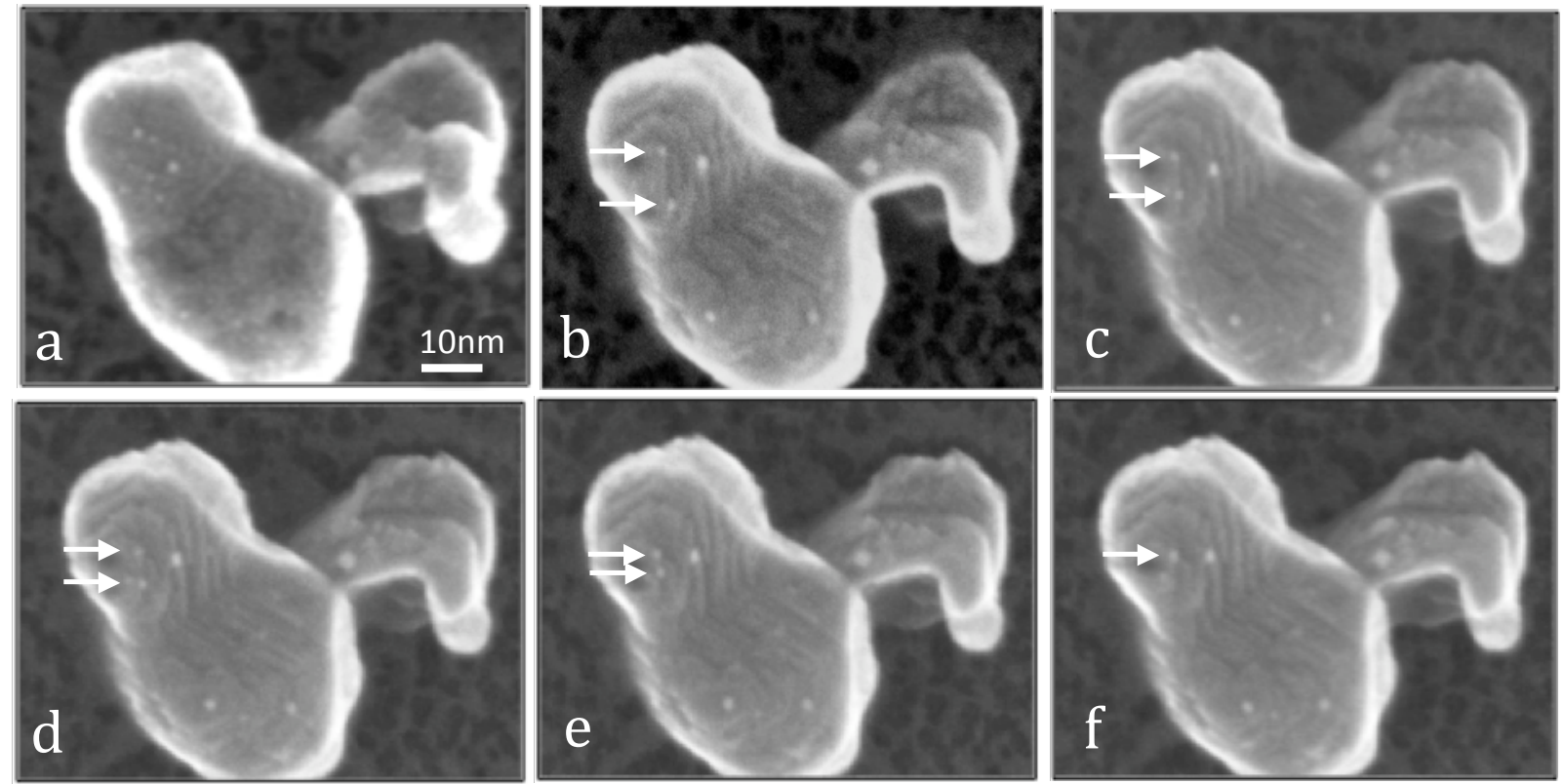

FIG. 2. Sequence of secondary electron images recorded at $300 \mathrm{kV}$ in the Hitachi HF-3000, with the same support particle held at $700^{\circ} \mathrm{C}$; several Au nanoparticles are visible on the surface; a) initial image at the start of sequence; b)-f) SE images after several minutes at $700^{\circ} \mathrm{C}$, showing the development of facets on the support surface and movement and coalescence of nanoparticles, as arrowed. 